\title{
TUMOR ODONTOGÊNICO CÍSTICO QUERATINIZANTE EM REGIÃO ANTERIOR DE MANDÍBULA: RELATO DE UM CASO CLÍNICO
}

Jocilene Cristina Evangelista BAGATELI, Keila RODRIGUES, Carolina Silva FARINAZZO, Nander de Moraes VALERIO, Newton César KAMEI

O Tumor Odontogênico Cístico Queratinizante, assim denominado por Reichart em 2002, foi descrito pela primeira vez por Phillpsen em 1956, sendo denominado na época como Queratocisto Odontogênico. Devido ao comportamento agressivo e às altas taxas de recidiva, atualmente o queratocisto é classificado como um tumor benigno, originado a partir do epitélio odontogênico e estroma fibroso, sem componente ectomesenquimal. O presente trabalho tem como objetivo relatar o caso do paciente A.M.C, gênero masculino, 49 anos de idade, leucoderma, encaminhado ao Projeto LEBU (Diagnóstico, tratamento e epidemiologia das doenças da cavidade bucal), da Universidade Estadual de Maringá, pelo posto de saúde local. Clinicamente observou-se abaulamento da cortical vestibular da mandíbula. Radiograficamente observou-se lesão radiolúcida, unilocular, com margem esclerótica definida. Devido às características da lesão a primeira hipótese foi Cisto Residual seguido por Tumor Odontogênico Cístico Queratinizante. O diagnóstico definitivo foi estabelecido após o exame microscópico, o qual é fundamental considerando que a determinação precisa das variantes microscópicas desta entidade está intimamente correlacionada com as diferenças nos índices de recorrência e na agressividade da lesão. De acordo com o laudo descrito, com presença de epitélio odontogênico pavimentoso estratificado paraqueratinizado e camada basal hipercromática disposta em paliçada, e juntamente com dados clínicos e radiográficos, chegou-se ao diagnóstico de Tumor Odontogênico Cístico Queratinizante. 